$06.1 ; 15.2$

\title{
Синергический эффект гибридного наполнителя на основе графеновых нанопластин и многостенных нанотрубок для повышения теплопроводности эпоксидного композита
}

\author{
(C) Т.А. Шалыгина ${ }^{1,2}$, А.В. Мележик ${ }^{3}$, А.Г. Ткачев ${ }^{3}$, С.Ю. Воронина ${ }^{1}$, В.Д. Ворончихин ${ }^{1}$, А.Ю. Власов ${ }^{1}$ \\ ${ }^{1}$ Научная лаборатория „Интеллектуальные материалы и структуры“, Сибирский государственный университет науки \\ и технологий им. акад. М.Ф. Решетнева, Красноярск, Россия \\ ${ }^{2}$ Сибирский федеральный университет, Красноярск, Россия \\ ${ }^{3}$ Тамбовский государственный технический университет, Тамбов, Россия \\ E-mail: leonova.ta@inbox.ru
}

Поступило в Редакцию 5 ноября 2020г.

В окончательной редакции 16 декабря 2020 г.

Принято к публикации 16 декабря 2020г.

\begin{abstract}
Получен гибридный теплопроводящий наполнитель на основе графеновых нанопластинок и многостенных нанотрубок для повышения теплопроводности эпоксидного связующего, проявляющий синергический эффект. Данный эффект достигается за счет встраивания нанотрубок между нанопластинами графена и формирования эффективных перколяционных сетей в композите. Установлена зависимость повышения теплопроводности эпоксидного композита от массового соотношения нанотрубок и нанопластин в смеси гибридного наполнителя. Обнаружено влияние концентрации гибридного наполнителя в эпоксидной матрице и способа смешивания нанопластин и нанотрубок на теплопроводность композита. Продемонстрирован синергический эффект между нанопластинами и нанотрубками, приводящий к пятикратному увеличению теплопроводности эпоксидных композитов при концентрации наполнителя $5 \mathrm{wt} . \%$.
\end{abstract}

Ключевые слова: синергический эффект, графеновые нанопластины, многостенные нанотрубки, теплопроводность.

DOI: 10.21883/PJTF.2021.07.50789.18609

Для полимерных композиционных материалов (ПКМ), армированных волокнистым наполнителем, используемых для изготовления различных конструкций космического назначения, потребность в повышении теплопроводности определяется как минимум двумя факторами. Первый обусловлен повышенной напряженностью структуры ПКМ, возникающей вследствие неравномерного нагрева космических конструкций от солнечного излучения, второй - локализацией поглощенной энергии в виде тепла в тонком поверхностном слое при радиационном воздействии на ПКМ, которая может привести к его расплавлению и испарению $[1,2]$. Поэтому в настоящее время представляет большой интерес поиск эффективного метода увеличения теплопроводности полимерных материалов. Наиболее результативным методом является внедрение различных теплопроводящих наполнителей в полимерную матрицу. Тем не менее технологические особенности производства изделий из ПКМ задают критерии отбора наполнителей и диапазон допустимых концентраций.

Перспективными теплопроводящими наполнителями являются углеродные материалы, причем гораздо большее внимание уделяется графену и углеродным нанотрубкам из-за чрезвычайно высокого аспектного соотношения, низкого веса и высоких значений теплои электропроводности [3-8]. Множество теоретических и экспериментальных работ посвящено исследованию зависимости теплопроводности полимерного композита от объемной доли, геометрических размеров, форм вводимых углеродных наполнителей и других факторов [9]. Также недавние исследования показали, что двумерный графен превосходит одномерные углеродные нанотрубки по эффективности улучшения механических, электрических и теплопроводящих свойств полимерных композитов [10-12].

Для углеродных наночастиц характерны сильные межмолекулярные взаимодействия, что приводит к их агрегации [13-15]. Однако наличие агрегатов углеродных наполнителей в структуре композита может приводить к противоречивым эффектам. С одной стороны, агрегация углеродных наночастиц способствует образованию проводящих и теплопроводящих перколяционных сетей. С другой стороны, слишком сильная агрегация приводит к образованию крупных, не связанных между собой агрегатов, в результате чего наблюдается снижение теплопроводности, увеличение пористости и ухудшение механических свойств композитов.

Для снижения агрегации нанотрубок или нанопластин графена применяются различные методы функционализации их поверхности, однако в большинстве случаев это приводит к возникновению дефектной структуры и ухудшению собственных теплопроводящих свойств наполнителя[16,17]. Кроме того, функционализация может привести к повышению смачиваемости наполнителя по- 
лимером, возникновению полимерной прослойки между углеродными частицами, при этом увеличивается контактное тепловое сопротивление на межфазных границах наполнитель-наполнитель. К настоящему времени многие пришли к выводу об эффективности применения гибридных наполнителей, которые способны проявлять синергический эффект [18-20]. Данный эффект позволяет достичь большего повышения теплопроводности при равных или меньших концентрациях вводимого гибридного наполнителя по сравнению с концентрацией отдельных компонентов.

В представленном исследовании была разработана методика улучшения теплопроводности эпоксидных композитов путем объединения одномерных многостенных нанотрубок (MWCNT) и двумерных графеновых нанопластин (GNP), выступающих в качестве теплопроводящего наполнителя. В полученной смеси MWCNT встраиваются между нанопластинами графена и препятствуют их агрегации, что ведет к построению более эффективных перколяционных сетей, приводящих к увеличению теплопроводности за счет проявления синергического эффекта гибридного наполнителя. Кроме того, в исследовании рассматривалось влияние соотношения MWCNT и GNP в смеси гибридного наполнителя, методики смешивания MWCNT и GNP и концентрации гибридного наполнителя на значение теплопроводности эпоксидных композитов.

Объектами исследования служили образцы на основе эпоксидного связующего марки Т67 производства АО „ИНУМиТ“ (Москва) с различной концентрацией $(0.1,1,2.5$ и 5 wt.\%) гибридного наполнителя, содержащего смесь GNP и MWCNT производства OОО „НаноТехЦентр“ (Тамбов). MWCNT представляют собой коаксиальные углеродные нанотрубки серии „Таунит-М“ диаметром 8-15 nm и длиной более $2 \mu \mathrm{m}$, полученные методом газофазного химического осаждения (CVD) (ТУ 2166-001-02069286-2006). GNP были получены путем интеркалирования природного графита раствором персульфата аммония в безводной серной кислоте, последующего терморасширения и обработки газообразным аммиаком; подробное описание технологии получения GNP приведено в патенте РФ 2693755. Синтезированные по данной методике GNP представляют собой многослойный графен, по данным просвечивающей электронной микроскопии (ПЭМ) число слоев варьируется в диапазоне от 5 до 25 (рис. 1). Для исследования влияния метода введения MWCNT в смесь GNP на эффективность построения перколяционных путей были приготовлены две серии $(D$ и $W)$ гибридного наполнителя.

Смесь серии $D$ (dry) была приготовлена при добавлении сухого порошка MWCNT в сухую сульфатную массу, являющуюся полупродуктом при синтезе GNP, полученную по указанной выше методике. При этом массовые соотношения GNP:MWCNT составили 80:20 и 60:40. После добавления MWCNT смесь размалывали в течение $15 \mathrm{~s}$ в ударной мельнице, заливали
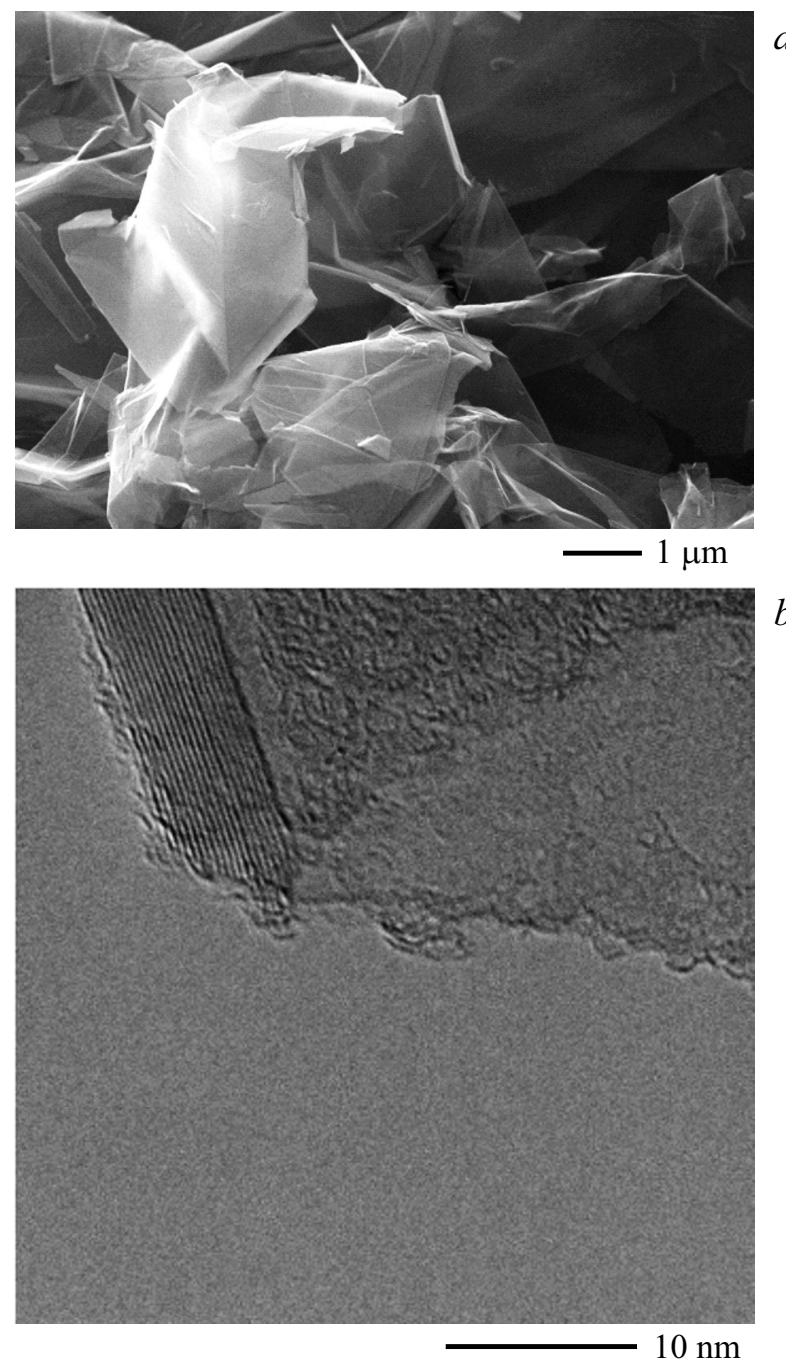

Рис. 1. СЭМ- $(a)$ и ПЭМ-изображения $(b)$ исходных GNP.

водой с небольшой добавкой изопропанола в качестве смачивателя, фильтровали и промывали на фильтре водой до отсутствия сульфат-ионов. После высушивания в сушильном шкафу смесь снова размалывали в ударной мельнице в течение $5 \mathrm{~min}$. Полученные сухие смеси гибридного наполнителя GNP/MWCNT(60/40)D и GNP/MWCNT(80/20)D характеризовались значениями насыпной плотности 38.6 и $48.4 \mathrm{~g} / 1$ соответственно.

На рис. 2 показано полученное методом сканирующей электронной микроскопии (СЭМ) изображение сухого гибридного наполнителя GNP/MWCNT(80/20)D. Исходя из данных микроскопии видно, что поверхность графеновых нанопластин покрыта углеродными нанотрубками, причем длина их составляет порядка $500 \mathrm{~nm}$. MWCNT длиной более $2 \mu \mathrm{m}$ остаются в виде отдельных агрегатов нанотрубок, переплетенных между собой. Вероятно, короткие нанотрубки присутствовали в виде небольшой фракции в исходном углеродном продукте Таунит-М, именно эта фракция в данном случае является полезной для дезагрегации графена. 
Смесь серии $W$ (watery) отличается тем, что MWCNT добавлялись в водную пасту GNP уже после фильтрации и промывки до отсутствия сульфат-ионов. Полученную пасту разбавляли водой до состояния однородной суспензии и обрабатывали блендером, затем продукт отфильтровывали и высушивали в сушильном шкафу, далее размалывали в ударной мельнице в течение $4 \mathrm{~min}$. Насыпная плотность сухой смеси гибридного наполнителя GNP/MWCNT(80/20)W имела значение $38.0 \mathrm{~g} / \mathrm{l}$.

Теплопроводность эпоксидных композитов с гибридным наполнителем была измерена с помощью дифференциального сканирующего калориметра DSC25, поддерживающего модуляцию теплового потока (производства TA Instruments, США), согласно ГОСТ Р 57830-2017. После добавления гибридного наполнителя в эпоксидное связующее осуществлялось его диспергирование посредством механического перемешивания в течение $10 \mathrm{~min}$. Затем смесь заливали в алюминиевые тигли TZero диаметром $5 \mathrm{~mm}$, высотой $3 \mathrm{~mm}$ и помещали в климатическую камеру для отверждения по заданной программе: $3 \mathrm{~h}$ при $80^{\circ} \mathrm{C}$ и $6 \mathrm{~h}$ при $120^{\circ} \mathrm{C}$. После отверждения тигли герметизировали с помощью ручного пресса. В качестве образца сравнения использовался точно такой же пустой герметичный тигель. Измерения выполнялись в атмосфере чистого азота в интервале температур от 15 до $70^{\circ} \mathrm{C}$ со скоростью $1^{\circ} \mathrm{C} / \mathrm{min}$, модуляция теплового потока характеризовалась периодом $40 \mathrm{~s}$ и амплитудой $\pm 0.5^{\circ} \mathrm{C}$.

На рис. 3 представлена зависимость теплопроводности от концентрации различных серий гибридного наполнителя в эпоксидных композитах. Видно, что добавление 5 wt.\% GNP/MWCNT(60/40)D привело к повышению теплопроводности композита до $1.04 \mathrm{~W} /(\mathrm{m} \cdot \mathrm{K})$ при температуре $25^{\circ} \mathrm{C}$, что на $520 \%$ превышает значение теплопроводности ненаполненного эпоксидного связующего. Кроме того, можно видеть, что методика смешивания GNP и MWCNT влияет на проявление синергического эффекта гибридного наполнителя. Добавление $2.5 \mathrm{wt} . \%$ наполнителей с одинаковым соотно-

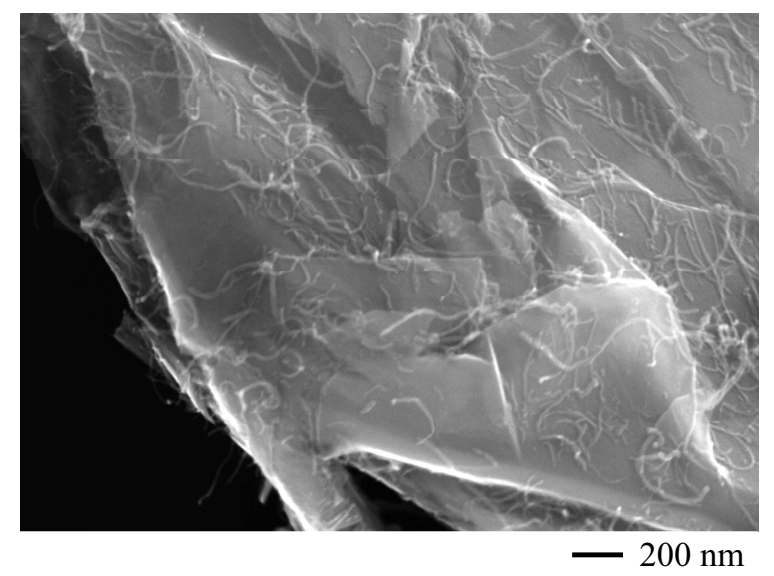

Рис. 2. СЭМ-изображение гибридного наполнителя GNP/MWCNT(80/20)D.

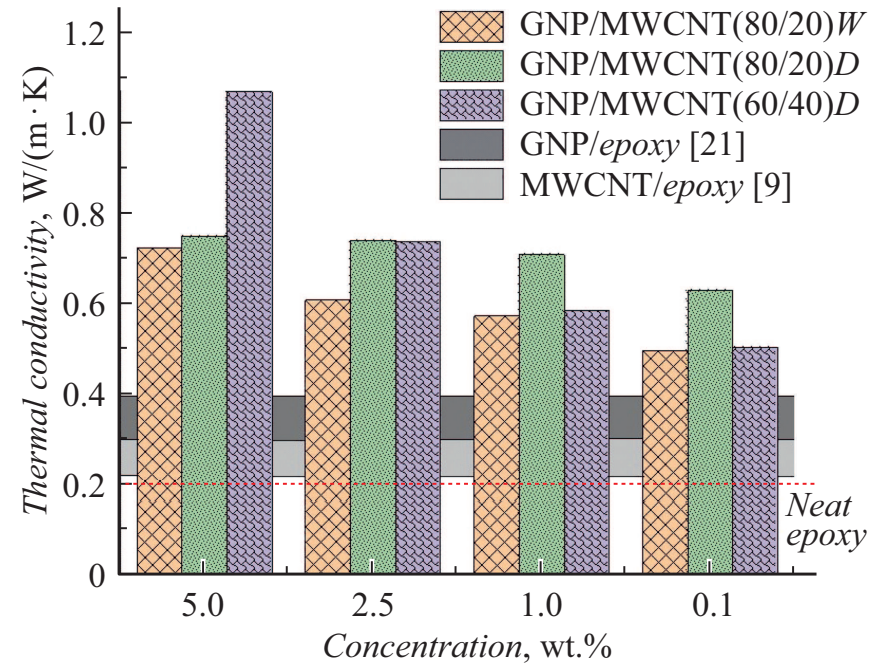

Pис. 3. Зависимость коэффициента теплопроводности эпоксидного композита от концентрации гибридных наполнителей GNP/MWCNT(60/40) $D$, GNP/MWCNT(80/20) $D$ и GNP/MWCNT(80/20)W. Для сравнения представлены данные для исходных MWCNT [9] и GNP [21].

шением GNP и MWCNT (80/20) серий $D$ и $W$ привело к повышению теплопроводности в образцах эпоксидного композита до 0.75 и $0.6 \mathrm{~W} /(\mathrm{m} \cdot \mathrm{K})$ соответственно. Однако при „сухом“ смешивании в соотношении (80/20) наблюдаются менее выраженная зависимость теплопроводности от концентрации и достижение перколяционного порога уже при $2.5 \mathrm{wt} . \%$. Вероятно, смешивание водных суспензий GNP и MWCNT в наполнителе серии $W$ позволяет более равномерно распределить нанотрубки между графеновыми нанопластинами, однако это приводит к повышению контактного сопротивления между ними и, как следствие, понижению эффективности увеличения теплопроводности.

Таким образом, в работе описаны две методики получения гибридного наполнителя GNP/MWCNT, различающиеся способом введения многостенных нанотрубок в смесь графеновых нанопластин. Показано, что фракция нанотрубок преимущественно меньшей длины встраивается между нанопластинами графена в смеси гибридного наполнителя. Обнаружено, что внедрение гибридного наполнителя с большим содержанием MWCNT (40 wt.\%) в эпоксидное связующее позволяет увеличить теплопроводность композита на $520 \%$ при концентрации наполнителя, составляющей $5 \mathrm{wt} . \%$.

\section{Финансирование работы}

Работа выполнена при реализации проекта № 05.607.21.0310 (идентификатор RFMEFI60719X0310) в рамках мероприятия 1.3 „Проведение прикладных научных исследований и разработок, направленных на создание продукции и технологий“ программы ФЦП „Исследования и разработки по приоритетным 
направлениям развития научно-технологического комплекса России на 2014-2020 гг.“.

\section{Конфликт интересов}

Авторы заявляют, что у них нет конфликта интересов.

\section{Список литературы}

[1] М. Панасюк, Л. Новиков, Модель космоса (КДУ, М., 2006), т. 1 , с. 854.

[2] Л.С. Новиков, В.Н. Милеев, Е.Н. Воронина, Л.И. Галанина, А.А. Маклецов, В.В. Синолиц, Поверхность. Рентгеновские, синхротронные и нейтронные исследования, № 3, 32 (2009).

[3] H. Huang, C.H. Liu, Y. Wu, S. Fan, Adv Mater, 17 (13), 1652 (2005). https://doi.org/10.1002/adma.200500467

[4] P. Kim, L. Shi, A. Majumdar, P.L. McEuen, Phys. Rev. Lett., 87 (21), 215502 (2001).

[5] C. Yu, L. Shi, Z. Yao, D. Li, A. Majumdar, Nano Lett., 5 (9), 1842 (2005). https://doi.org/10.1021/n1051044e

[6] S. Stankovich, D. Dikin, G.H.B. Dommett, K.M. Kohlhaas, E.J. Zimney, E.A. Stach, R.D. Piner, S.B.T. Nguyen, R.S. Ruoff, Nature, 442 (7100), 282 (2006). https://doi.org/10.1038/nature04969

[7] L.M. Veca, M.J. Meziani, W. Wang, X. Wang, F. Lu, P. Zhang, Y. Lin, R. Fee, J.W. Connell, Y.-P. Sun, Adv. Mater., 21 (20), 2088 (2009). https://doi.org/10.1002/adma.200802317

[8] P. Kumar, S. Yu, F. Shahzad, S.M. Hong, Y.-H. Kim, C.M. Koo, Carbon, 101, 120 (2016). https://doi.org/10.1016/j.carbon.2016.01.088

[9] Z. Han, A. Fina, Prog. Polym. Sci, 36 (7), 914 (2011). https://doi.org/10.1016/j.progpolymsci.2010.11.004

[10] K.M.F. Shahil, A.A. Balandin, Nano Lett., 12 (2), 861 (2012). https://doi.org/10.1021/n1203906r

[11] C.C. Teng, C.C.M. Ma, C.H. Lu, S.Y. Yang, S.H. Lee, M.C. Hsiao, Carbon, 49 (15), 5107 (2011). https://doi.org/10.1016/j.carbon.2011.06.095

[12] M.R. Zakaria, M.H. Abdul Kudus, H. Md. Akil, M.Z. Mohd Thirmizir, Composites B, 119, 57 (2017). https://doi.org/10.1016/j.compositesb.2017.03.023

[13] Y. Si, E.T. Samulski, Chem. Mater., 20 (21), 6792 (2008). https://doi.org/10.1021/cm801356a

[14] Y. Si, E.T. Samulski, Nano Lett., 8 (6), 1679 (2008). https://doi.org/10.1021/n1080604h

[15] D. Li, M.B. Muller, S. Gilje, R.B. Kaner, G.G. Wallace, Nature Nanotech., 3 (2), 101 (2008). https://doi.org/10.1038/nnano.2007.451

[16] S.-Y. Yang, C.-C.M. Ma, C.-C. Teng, Y.-W. Huang, S.-H. Liao, Y.-L. Huang, H.-W. Tien, T.-M. Lee, K.-C. Chioub, Carbon, 48 (3), 592 (2010). https://doi.org/10.1016/j.carbon.2009.08.047

[17] K.A. Worsley, I. Kalinina, E. Bekyarova, R.C. Haddon, J. Am. Chem. Soc., 131 (50), 1253 (2009). https://doi.org/10.1021/ja906267g

[18] Sh. Zhang, Sh. Yin, Ch. Rong, P. Huo, Zh. Jiang, G. Wang, Eur. Polym. J. 49 (10), 3125 (2013). https://doi.org/10.1016/j.eurpolymj.2013.07.011

[19] H.S. Kim, J.H. Kim, C.-M. Yang, S.Y. Kim, J. Alloys Compd., 690, 274 (2017). https://doi.org/10.1016/j.jallcom.2016.08.141
[20] A. Badakhsh, Y.-M. Lee, K.Y. Rhee, C.W. Park, K.-H. An, B.-J. Kim, Composites B, 175, 107075 (2019). https://doi.org/10.1016/j.compositesb.2019.107075

[21] F. Wang, L.T. Drzal, Y. Qin, Z. Huang, J. Mater. Sci., 50 (3), 1082 (2015). DOI: 10.1007/s10853-014-8665-6 